\title{
A FORMAÇÃO DO ALUNO LEITOR NO PROEJA: INTERFACES COM A FORMAÇÃO, EXPERIÊNCIA E PRÁTICA DOCENTE
}

\author{
Soraya Rocha Melo \\ Graduada em Pedagogia pela Universidade Estadual do Norte de Minas Gerais - UNIMONTES - \\ Mestre em Educação - Universidade Estadual do Sul da Bahia - UESB \\ e-mail: soraya.r.m.63@gmail.com \\ Denise Brito Barreto \\ Mestre em educação - FACED/UFBA \\ Doutora em Educação - FACED/UFBA \\ Pós-doutorado em Educação - FPCE/ Universidade de Coimbra \\ e-mail: deniseabrito@gmail.com \\ Daniele Farias Freire \\ Licenciada em Pedagogia, com especialização em Metodologia do Ensino Superior; \\ Mestre em educação na linha de políticas e gestão da educação pela FACED/UFBA \\ Doutora em educação na linha de currículo e (in)formação pela FACED/UFBA \\ Coordena o Grupo de Estudos em Formação, Diferença e Subjetividades CNPq/UESB. \\ e-mail: danielefreire.uesb@gmail.com
}

\begin{abstract}
RESUMO
Este artigo busca discutir os desafios à formação do aluno leitor no Programa de Educação de Jovens e Adultos (PROEJA), considerando as interfaces entre a formação docente, a experiência do professor nessa modalidade de ensino e as suas práticas pedagógicas. Para tanto, realizamos uma pesquisa ex-post-facto, por ser considerada a mais apropriada na procura da compreensão de ações ocorridas em determinado tempo e espaço e onde somente compete a sua descrição. Utilizamos Freire (2005), Nóvoa (2016), Kleiman (2011) e Therrien (2002), entre outros, como embasamento teórico. Considerando a coexistência de diálogos e a trama social constituída de forma espontânea, utilizamos a entrevista e o questionário, cujas interpretações estiveram pautadas na Análise de Conteúdo (AC) apoiando-se em Bardin (2009). Assim, investigamos as práticas docentes ocorridas no PROEJA de um Curso Técnico em Comércio, no Instituto Federal do Norte de Minas Gerais (IFNMG), de uma cidade do interior deste estado, contando com a participação de seis professores, seguindo os seguintes critérios: ter trabalhado na turma do PROEJA e ter conhecimento das propostas para trabalho com esta modalidade de ensino. Deste trabalho, emergiram como categorias de análise: (1) a experiência e a formação para a docência na EJA; (2) a contribuição do curso de formação para a construção do professor leitor e (3) a Prática Pedagógica para leitura no PROEJA. Esta pesquisa sugere um olhar diferenciado para os anseios, as necessidades, os interesses, as motivações, as condições de vida e outras particularidades dos discentes jovens e adultos que buscam formação em um curso técnico do PROEJA.
\end{abstract}

Palavras-chave: Formação de professores; Formação do leitor; Prática pedagógica.

\section{FORMATION OF THE STUDENT READER AT THE PROEJA: INTERFACES WITH EDUCATION, EXPERIENCE AND TEACHING PRACTICE}

\begin{abstract}
This article aims to discuss the challenges of the student reader formation in the Youth and Adult Education Program (PROEJA), considering the interfaces between teacher training, teacher experience in this teaching modality and their pedagogical practices. Therefore, an ex-post-facto research was carried out, since it was considered the most appropriate in the search for the understanding of actions that occur in a given time and space in which only their description is relevant. Freire (2005), Nóvoa (2016), Kleiman (2011) and Therrien (2002), among others, were used as theoretical basis. Considering the coexistence of dialogues and the spontaneously
\end{abstract}


constructed social network, an interview and a questionnaire were used, whose interpretations were based on Bardin's (2009) Content Analysis (CA). Thus, the teaching practices of the PROEJA of a Technical Course in Commerce, in the Instituto Federal do Norte de Minas Gerais (IFNMG), of a city in the interior of this state were investigated, with the participation of six teachers, following the following criteria: having worked in the PROEJA and having knowledge of the proposals to work with this teaching modality. From our research, the following categories of analysis emerged: (1) experience and training for teaching in the EJA; (2) the contribution of the training course for the construction of the teacher reader and (3) the Pedagogical Practice for reading in the PROEJA. This research suggests a different look at the yearnings, needs, interests, motivations, living conditions and other particularities of young and adult students who seek training in a technical course of the PROEJA.

Keywords: Teacher training; Reader formation; Pedagogical practice.

\section{LA FORMACIÓN DEL ALUMNO LECTOR EN EL PROEJA: INTERFACES CON LA FORMACIÓN, EXPERIENCIA Y PRÁCTICA DOCENTE}

\section{RESUMEN}

Este artículo busca discutir los desafíos para la formación del alumno lector en el Programa de Educación de Jóvenes y Adultos (PROEJA), considerando las interfaces entre la formación docente, la experiencia del profesor en esa modalidad de enseñanza y sus prácticas pedagógicas. Para tanto, realizamos una investigación ex-post-facto, por ser considerada la más apropiada en la búsqueda de la comprensión de acciones ocurridas en determinado tiempo y espacio y donde solamente compete su descripción. Utilizamos Freire (2005), Nóvoa (2016), Kleiman (2011) y Therrien (2002), entre otros, como embasamiento teórico. Considerando la coexistencia de diálogos y el tejido social constituido de forma espontánea, utilizamos la entrevista y el cuestionario, cuyas interpretaciones se pautaron en el Análisis de Contenido (AC) apoyándose en Bardin (2009). Así, investigamos las prácticas docentes ocurridas en el PROEJA de un Curso Técnico en Comercio, en el Instituto Federal do Norte de Minas Gerais (IFNMG), de una ciudad del interior de este estado, contando con la participación de seis profesores, siguiendo los criterios siguientes: haber trabajado en el PROEJA y conocer las propuestas de trabajo con esta modalidad de enseñanza. De este trabajo, emergieron como categorías de análisis: (1) la experiencia y la formación para la docencia en la EJA; (2) la contribución del curso de formación para la construcción del profesor lector y (3) la Práctica Pedagógica para la lectura en el PROEJA. Esta investigación sugiere una mirada diferenciada para los deseos, necesidades, intereses, motivaciones, condiciones de vida y otras particularidades de los discentes jóvenes y adultos que buscan una formación en un curso técnico do PROEJA.

Palabras clave: Formación de profesores; Formación del lector; Práctica pedagógica.

\section{Introdução}

A formação do aluno leitor é uma das grandes preocupações que aparecem nos discursos produzidos pela escola. Sabemos que essa formação está associada aos diversos fatores, dentre eles, o desenvolvimento da atitude leitora dos professores, o que tem se tornado um grande desafio aos cursos de formação docente.

Partindo do pressuposto que há uma íntima relação entre a prática leitora dos professores e a formação do aluno leitor, buscamos, neste artigo, discutir os desafios à formação do aluno leitor no Programa de Educação de Jovens e Adultos (PROEJA), 
considerando as interfaces entre a formação docente, a experiência do professor nessa modalidade de ensino e as suas práticas pedagógicas.

Para realização deste trabalho utilizamos uma pesquisa ex-post-facto, escolha justificada por ser considerada a mais apropriada na procura da compreensão de ações ocorridas em determinado tempo e espaço e onde somente compete a sua descrição. Nesse caso específico, investigamos as práticas docentes ocorridas no PROEJA de um Curso Técnico em Comércio, no Instituto Federal do Norte de Minas Gerais (IFNMG) de uma cidade do interior deste estado e as suas contribuições na formação autônoma e crítica de alunos leitores nesse programa.

A abordagem utilizada nessa pesquisa foi de natureza qualitativa, uma vez que ela "responde as questões muito particulares, preocupando-se com um nível de realidade que não pode ser somente quantificado" (MINAYO, 2000, p. 21).

Os sujeitos que participaram da pesquisa foram escolhidos considerando o grau de envolvimento no contexto de materialização do trabalho proposto. Nesses termos, para os critérios estabelecidos na escolha dos docentes colaboradores consideramos o trabalho realizado anteriormente em turma do PROEJA, objeto deste estudo, e possuir conhecimento das propostas para trabalho com esta modalidade de ensino. Os professores colaboradores estavam atuando nas seguintes disciplinas: química, matemática, língua portuguesa, física, história/sociologia e geografia.

A busca de informações sobre a questão investigada suscitou o uso de instrumentos que possibilitaram a coexistência de diálogos, expressando a trama social constituída de forma espontânea, oferecendo subsídios relevantes e instigantes para a definição dos rumos da pesquisa. A partir desse nível de entendimento, como instrumentos para a coleta de dados utilizamos a entrevista, com o objetivo de analisar as concepções dos docentes e os diferentes pontos de vista sobre uma mesma realidade, pois essa técnica apresenta um caráter interativo e dialético, além de fazer emergir questões que não estão previamente definidas, possibilitando esclarecimentos e correções; e o questionário, utilizado para colher informações com os professores do curso. Segundo Günther (2003), pode ser definido questionário como técnica de investigação composta por um número mais ou menos elevado de questões apresentadas por escrito às pessoas, tendo por objetivo o conhecimento de opiniões, crenças, sentimentos, interesses, expectativas, situações vivenciadas, entre outros fatores. 
Para a análise e transcrição dos dados coletados através do questionário e da entrevista utilizamos a Análise de Conteúdo (AC) que segundo Bardin (2009, p. 41) pode ser entendida como:

Um conjunto de técnicas de análise de comunicações visando obter procedimentos sistemáticos e objetivos de descrição do conteúdo das mensagens, indicadores (quantitativos ou não) que permitam a inferência de conhecimentos relativos às condições de produção/recepção (variáveis inferidas) destas mensagens.

Conforme alertou Bardin (2009), a análise de conteúdo é dividida em três fases: 1) pré-análise, 2) exploração do material ou descrição análitica e 3) tratamento dos resultados, inferência e interpretação, que ocorre quando as respostas são categorizadas para que os dados brutos se tornem então significativos.

Na presente pesquisa, houve a categorização das respostas dos docentes e do curso Técnico em Comércio do PROEJA/IFNMG, quando, durante a exploração dos questionários e entrevistas emergiu a tentativa, seguindo as orientações de Bardin, de compreender o sentido da comunicação escrita e oral, como um receptor normal e também buscando nas entrelinhas, através de seus "significados" e "significantes" atingir outros "significados" que se supõe estarem relacionadas às questões políticas, sociais, psicológicas e culturais que permeiam a vida de todo ser humano.

Bardin (2009) ao descrever os métodos de análise de conteúdo esclarece que estes agrupam-se em duas categorias: o método quantitativo que se baseia na frequência do aparecimento de certas características de conteúdo e o método qualitativo que tem como unidade de informação de base a presença ou ausência, semelhanças ou diferenças de uma característica. Apropriamos destas orientações e, na pesquisa realizada, foi utilizada a classificação dos temas em categorias que consistiu no agrupamento segundo semelhanças e diferenças, reagrupando, posteriormente, em função das caracteristicas comuns. A esse tipo de classificação se denomina análise categorial.

$\mathrm{Na}$ presente pesquisa apresentamos a categorização das respostas dos docentes quando, durante a exploração dos questionários e entrevistas procuramos, seguindo as orientações de Bardin, compreender o sentido da comunicação escrita e oral, como um receptor normal e também buscando nas entrelinhas, através de seus "significados" e "significantes" atingir outros "significados" que, supomos, estão relacionadas às questões políticas, sociais, psicológicas e culturais que permeiam a vida de todo ser humano. 
As informações e ideias mais importantes que surgiram no decorrer das respostas dadas pelos docentes foram ordenadas nas seguintes categorias de análise mapeadas de acordo com uma descrição analítica: (1) experiência e formação para a docência na EJA; (2) contribuição do curso de formação para a construção do professor leitor e (3) Prática Pedagógica para leitura no PROEJA.

Para manter o anonimato dos participantes desta pesquisa, os professores foram identificados com os códigos P1, P2, P3, P4, P5, P6. Ao interpretar os dados, que são a representação das falas, respostas, atitudes dos pesquisados, buscamos uma apreensão dos seus significados, levando em conta o contexto do qual se encontram inseridos.

\section{Experiência e formação para a docência na EJA}

Como materialidade linguística, utilizamos nesta análise os discursos dos docentes, sujeitos desta pesquisa, quando fizeram referência às formações recebidas, que são os cursos de graduação em nível superior nos quais se licenciaram. Uma vez que esta formação ocorreu em um lugar social, uma escola, e os docentes são sujeitos de aprendizagem, será levado em consideração a relação deles com a formação, a partir dos contextos onde se encontram e o sentido que atribuem, levando em consideração que esta formação foi perpassada por memórias discursivas distintas e interpeladas pelo jogo do poder-saber enquanto prática social. Conforme afirma Ferrarezi (2010, p. 14):

O sentido de uma palavra é totalmente determinado por seu contexto. De fato, há significações possíveis quantos contextos possíveis (grifos nossos). No entanto nem por isso a palavra deixa de ser uma. Ela não se desagrega em tantas palavras quantos forem os contextos nos quais ela pode se inserir.

Concebemos como contexto a temática e tudo que envolve a experiência e a formação inicial e continuada para a Educação de um modo geral e para a EJA de forma específica, onde estão inseridos os sujeitos de pesquisa, sendo que “[...] o texto que precede e sucede o próprio texto, o texto que se junta e que referencia o texto, num entrelaçar de palavras em textos que acabam formando o complexíssimo conjunto de sinais interligados que procuramos entender quando nos comunicamos" (FERRAREZI, 2010, p. 116). 
Ainda conforme Ferrarezi (2010), o sentido tem forte relação com o contexto histórico e social em que os sujeitos estão inseridos, para Bueno (2006) o perfil do professor e sua experiência docente é atributo fundamental na melhoria da qualidade do ensino.

O questionário respondido pelos seis professores, foi um fator que justificou a realização desta pesquisa, quando procuramos conhecer se estes sujeitos possuíam experiência na docência e na docência em EJA, área em que ministravam aulas e se haviam cursado alguma formação para atuar na EJA, mesmo considerando, assim como afirma Cunha (2000), ser impossível fracionar a imagem do bom professor, pois vários aspectos se entrelaçam e certamente se inter-relacionam na prática pedagógica. A tabela a seguir permite-nos uma síntese dessas informações:

\section{TABELA - Perfil dos colaboradores - Docentes do Curso Técnico em Comércio do} PROEJA/IFNMG de uma cidade do interior de Minas Gerais

\begin{tabular}{|c|c|c|c|c|}
\hline DOCENTE & $\begin{array}{c}\text { EXPERIÊNCIA } \\
\text { NA } \\
\text { DOC } \hat{E N C I A} \\
\text { (anos) }\end{array}$ & $\begin{array}{c}\text { EXPERIÊNCIA } \\
\text { NA } \\
\text { DOCÊNCIA } \\
\text { EM EJA }\end{array}$ & $\begin{array}{c}\text { ÁREA DE } \\
\text { ATUAÇÃO }\end{array}$ & $\begin{array}{c}\text { FORMAÇÃO } \\
\text { EM EJA }\end{array}$ \\
\hline P1 & 25 & 0 & Química & Não \\
\hline $\mathbf{P 2}$ & 10 & 4 & $\begin{array}{l}\text { História e } \\
\text { Sociologia }\end{array}$ & Não \\
\hline $\mathbf{P 3}$ & 17 & 0 & Português & Não \\
\hline $\mathbf{P 4}$ & 5 & 0 & Geografia & Não \\
\hline P5 & 13 & 0 & Matemática & Não \\
\hline P6 & Sim & 0 & Física & Não \\
\hline
\end{tabular}

Dos seis docentes participantes da pesquisa somente 1 (um) informou possuir experiência anterior a EJA. A maioria declarou ter se iniciado como professor nesta modalidade de ensino no curso Técnico em Comércio do IFNMG/Campus Januária. Percebemos, assim, a necessidade de investimento na formação e capacitação continuada de professores para atuar no PROEJA para que possam, de fato, contribuir de forma mais significativa com a aprendizagem dos jovens e adultos, atendendo-os em todas as suas especificidades.

De acordo com a declaração denominada "Marco da Ação de Dacar", que ocorreu em abril de 2000, em Dacar, no Senegal:

[...] toda criança, jovem e adulto tem direito humano de se beneficiar de uma educação que satisfaça suas necessidades básicas de aprendizagem, no melhor e mais pleno sentido do terno, e que inclua aprender a 
aprender, a fazer a conviver e a ser. É uma educação que se destina a captar os talentos e o potencial de cada pessoa e desenvolver a personalidade dos alunos, para que possam melhorar suas vidas e transformar suas sociedades [...] assegurar que as necessidades de aprendizagem de todos os jovens e adultos sejam atendidas pelo acesso eqüitativo à aprendizagem apropriada, à habilidade para a vida e a programas de formação para a cidadania. (DECLARAÇÃO DE JOMTIEN apud PROPOSTA CURRICULAR, 2002, p. 21).

Vindo ao encontro das intenções dessa proposta é possível considerar a importância da experiência do professor para trabalhar na EJA, assim como a necessidade e urgência em investimento na formação e capacitação dos docentes para atuar nesta modalidade de ensino. É importante que o ensino da EJA não copie o mesmo modelo de aula desenvolvida no ensino regular. Entendemos que a formação docente específica para atuar nesta modalidade de ensino permitirá melhor adequação das aulas às condições do aluno que participa da EJA, por se tratar de um público que requer propostas curriculares diferenciadas.

Os resultados em relação a estes questionamentos demonstraram que todos eles possuíam mais de 10 anos de experiência docente no ensino regular. Assim, levando em consideração que, de acordo com Veiga e Silva (2010), o problema da formação profissional no ensino superior perpassa pelo papel do professor nesta formação e de sua formação continuada, os docentes foram questionados sobre a sua participação em cursos para trabalhar na EJA e obtivemos como respostas.

Infelizmente não. Já havia trabalhado em programas anteriores para jovens e adultos como "Caminho para a Cidadania" e "Acertando o Passo", em todos estes momentos confesso que senti bastante dificuldades (P1)

Não fiz nenhum curso, mas fui aprendendo a trabalhar na prática, na troca de experiência com os colegas (P2).

No discurso dos docentes há uma pluralidade de saberes que informa sua trajetória profissional e indica que a qualificação para educar jovens e adultos tem deixado a desejar, uma vez que eles aprendem na prática e na troca de experiência com os colegas. Situação que, no entendimento de Cruz (1994, p. 115), "tendo em vista sua formação acadêmica bastante deficiente, corre o professor o risco de, nessa prática, tornar-se razoavelmente capaz de exercer o magistério de forma honesta e interessada, porém, desempenhando o papel de reprodutor do sistema social vigente". 
Curso não. Porém, como lecionava em uma instituição que só trabalhava com EJA, constantemente fazíamos trabalhos e estudos voltados para este público (P3).

Não. Mas aprendi muito com meus colegas (P4).

O aprendizado informal, aquele que acontece na observação do trabalho do colega foi a forma encontrada pelos docentes investigados para se capacitarem, como pode ser comprovado no discurso de P3 e P4.

Infelizmente não tive esta oportunidade, mas na troca de experiência com os colegas vou levando e cada dia melhorando mais minhas aulas (P5).

Não. Infelizmente, porque isso faz falta (P6)

Mardegan (2013, p. 1) conceitua aprendizado informal como aquela aprendizagem que "acontece naturalmente e envolve a busca de entendimento, conhecimento ou habilidade que acontece além dos programas de ensino formais, como cursos estruturados e treinamentos",

Conforme Ducrot (1987) em um dito, alguns pressupostos ficam subentendidos. Estes subentendidos dizem respeito ao entendimento que pode ser dada pelo destinatário do discurso. Numa análise das respostas dos professores, a palavra "infelizmente", conforme sublinhamos, é recorrente no discurso de muitos deles, ficando subentendido que todos eles se ressentem de não terem tido a oportunidade de realizar qualquer curso que os capacitassem para atuar na EJA, o que normalmente é compensado na troca de experiências com os colegas que também não se sentem preparados para a docência direcionada especificamente aos discentes jovens e adultos.

Implicitamente, na fala desses docentes fica evidente o interesse em participar de cursos que os capacitem para promover uma aprendizagem eficiente e que possibilite o processo de inclusão dos alunos jovens e adultos.

Segundo Ferrão (2004, p. 35), “o perfil do formador abarca um conjunto de competências entre as quais são: competências pedagógicas; competências psico-social; e competências técnicas", preocupação que parece não ter norteado a formação acadêmica de todos os professores que atuaram nesse Curso Técnico em Comércio, pois, além da graduação em cursos de licenciatura, nenhum deles tiveram oportunidade de cursar uma complementação para atuar na modalidade EJA. 
Therrien (2002) descreve que para uma docência ser eficaz o professor precisa saber articular sua experiência com as dimensões políticas e pedagógicas para que possa promover transformações na vida dos educandos. Ocorre que a formação, que tem o intuito de capacitar o professor para promover esta articulação com a EJA, na realidade, está sempre ficando à margem se for realizada uma comparação com a formação para atuar nas demais modalidades de ensino (SANTOS; VIANA, 2011).

As Diretrizes Curriculares para a EJA (BRASIL, 2000) também demonstram preocupação com a formação de professores para atuar nesta modalidade de ensino. Podemos perceber que a avaliação (regras de certificação de competências) e formação de professores, juntamente com a organização e seleção de conteúdos formam o tripé das Diretrizes Curriculares Nacionais para a Educação de Jovens e Adultos (Resolução CNE/CBE n. 01 e 5/07/2000).

O Conselho Nacional de Educação - CNE, em 2001 buscou regulamentar as normas para a reformulação dos cursos de licenciatura e daqueles voltados para a formação de professores das séries iniciais do ensino fundamental, em nível superior, o que incidiu sobre aspectos da formação de professores para esta modalidade de ensino. Dados mais recentes, referentes ao Censo Escolar 2010, demonstram que as características em relação a formação de professores para a EJA sofreu grandes mudanças na primeira década do século XXI, pois, em 2010, cerca de $80 \%$ dos professores que atuavam com jovens e adultos tinham formação em nível superior, índice bastante superior ao verificado em 2001, quando esse percentual era de 66\% (INEP, 2010) .

Mesmo assim, segundo Nóvoa (2001), esse contingente de professores continua a apresentar lacunas em sua formação, pois os currículos dos cursos de formação de professores não consideram as peculiaridades da EJA. A propósito deste assunto vale citar pesquisa desenvolvida por Gatti (2009), cujo objetivo foi analisar a estrutura curricular e as ementas de 165 cursos presenciais de instituições de ensino superior, nas áreas de Pedagogia, Língua Portuguesa, Matemática e Ciências Biológicas, e demonstrou que, dentre os 71 cursos de Pedagogia analisados, apenas 1,6\% das disciplinas obrigatórias tratavam de conhecimentos relativos à EJA.

O estudo confirmou, também, a existência de poucos cursos superiores que habilitam educadores para atuar na andragogia ${ }^{1}$ uma vez que dos 1.306 cursos de

\footnotetext{
${ }^{1}$ Andragogia é um conceito de educação voltada para o adulto. De acordo com Knowles (1973) é a arte ou ciência de orientar adultos a aprender.
} 
Pedagogia existentes no Brasil, apenas dezesseis deles oferecem habilitação em Educação de Jovens e Adultos.

Estes dados demonstram que os professores da EJA continuam a enfrentar inúmeros desafios para se manterem atualizados e desenvolverem práticas pedagógicas eficientes, o que demanda um repensar sobre a formação técnica e política de professores para atuarem na educação de jovens e adultos.

Uma vez que as experiências dos professores podem contribuir com a dinâmica das aulas, cabe considerar que os conhecimentos necessários para a construção de novos saberes pelos educandos estão sendo construidos pelos professores da EJA/PROEJA no dia a dia de sua prática pedagógica. Sendo assim, ressentimos a falta de formação que possibilite ao professor garantir a importante relação teoria-prática, necessária e importante para o bom desempenho docente. Enfim, como bem descreve Moura (2007), torna-se necessário capacitar tecnicamente os professores para atuarem na EJA a partir da inserção nas matrizes curriculares dos cursos de licenciatura as disciplinas que possibilitem preparar esses professores para atuarem e refletirem sobre as especificidades e importância desta modalidade de ensino.

Para Freire (2005, p. 80), a formação do professor diz respeito ao saber fazer, uma vez que "[...] como professor preciso me mover com clareza. Preciso conhecer as diferentes dimensões que caracterizam a essência da prática, o que me pode tornar mais seguro do meu próprio desempenho".

Entendemos, assim, que os professores precisam receber uma formação que lhes permitam desenvolver uma competência que vai além do uso dos métodos e técnicas de ensino, mas que adquiram conhecimentos e habilidades que os capacitem para auxiliarem seus alunos no desenvolvimento de uma consciência critica e reflexiva.

Competência que foi, historicamente, deixada de lado quando se pensou na educação de jovens e adultos, conforme destaca Moura, (2007, p. 63), ao estudar a trajetória da EJA:

Nos cursos oferecidos pelas instituições formadoras, tanto em nível médio como superior, sentimos a necessidade de aprofundamentos teórico-práticos no que se refere à educação de jovens e adultos, presentes na fragilidade da formação do professor, devido a não inclusão da EJA, nos currículos das instituições, como também a dificuldade de colocar em prática os princípios políticos e pedagógicos defendido pela LDB, por falta de subsídios que deveriam ter sido adquiridos na formação inicial desse professor. 
Neste contexto ao se pensar na formação do professor para atuar na Educação de Jovens e Adultos, devemos levar em consideração a necessidade constante de capacitação. "Há de se lembrar que a preparação técnica, a ampliação do conhecimento e a atualização exigem um exercício frequente e diário por parte do educador e do sistema no qual ele está inserido" (RODRIGUES, s.d., p. 5). Sendo assim, a formação e a capacitação contínua do professor é algo indiscutível para se elevar a qualidade da educação que é ofertada aos nossos educandos.

\section{Contribuição do curso de formação para a construção do professor leitor}

A escola, de um modo geral, tem o importante papel de transmitir aos seus educandos o conhecimento a respeito da importância da leitura e é função do professor ser o mediador nesse processo de conhecimento e aprendizado. Para isso, é necessário que o professor tenha o conhecimento das teorias que explicam o ato de ler. Neste contexto, é necessário que o currículo dos cursos de formação de professores "dediquem espaços significativos a essa informação" (FOUCAMBERT, 1994, p. 10). No entanto, conforme estes docentes os cursos de licenciatura não contribuíram para a construção de um professor leitor.

Para Silva (1995, p. 109), educa-se com o exemplo; para formar alunos leitores os professores precisam ser também leitores, uma vez que "a condição básica para ensinar o aluno a ler diz respeito à capacidade de leitura do próprio professor”. Assim, o processo ensino-aprendizagem da leitura na escola demanda mudança da concepção que o professor tem sobre a leitura, bem como o papel que a mesma ocupa no projeto curricular da escola, para isso, é necessário que os professores se envolvam com a leitura enquanto objeto de conhecimento (SOLÉ, 1998). A partir das respostas de alguns dos docentes investigados e que são transcritas a seguir, foi possível identificar que no curso de formação de professores eles liam por exigência específica de domínio do conteúdo de cada disciplina do curso de graduação para fazer as avaliações, ou seja, tinham como objetivo a memorização do conteúdo.

$\mathrm{Na}$ faculdade eu lia para fazer as provas, afinal tinha que dominar o conteúdo, demonstrar o conhecimento nas avaliações para ser aprovado no final do período (P1).

O Curso de Licenciatura por si só, já nos obriga a ler muito, tanto por conta da parte específica, mas muito mais por conta da parte pedagógica. 
Qualquer professor, de qualquer disciplina, precisa que seu aluno consiga ler para que consiga aprender, para conseguir interpretar e se posicionar diante de um texto (P3).

Os professores sempre falavam sobre a importância de ler muito para conseguirmos dominar o conteúdo que iríamos trabalhar em sala de aula quando nos formássemos. Exigiam assim que lêssemos os conteúdos trabalhados em sala de aula, propunham discussão dos mesmos para que pudéssemos aprender e demonstrar este conhecimento nas avaliações e em nossas falas durante os momentos de discussão coletiva dos temas (P5).

Ao analisar as respostas dos docentes P1, P3 e P5, fica evidenciado que no curso de formação de professores houve o destaque do caráter obrigatório da leitura voltada sempre para a realização de atividades avaliativas e/ou específica para a disciplina ministrada por cada docente, inibindo ou limitando as possibilidades de realizar leitura de forma prazerosa, pois era proposta, quase sempre, a leitura de textos. Isso, no entendimento de Silva (1995, p. 104),

[...] Ao invés de estimular a reflexão e a busca de conhecimentos, de promover o prazer e desenvolver a criticidade, o ensino da leitura é regido por pretexto altamente questionáveis, congelando ou mesmo aniquilando o potencial de atribuição de significado à palavra escrita, que os alunos trazem para a situação de aprendizagem escolar.

Surge um complemento, para um dos docentes, que reforça a opinião de que o curso de licenciatura não contribuiu para a formação de professores leitores e complementa que "o curso de graduação deve trazer essa discussão sobre a importância da leitura em todos os seus eixos formadores. Assim cada eixo poderia se dedicar às formas de linguagens que mais lhe são características" (P2).

Nas respostas de dois docentes participantes podemos notar que eles encontram dificuldades para trabalhar leitura com os alunos jovens e adultos e admitem que estas dificuldades estão relacionadas com a falta de preparo dos próprios professores e que a formação continuada seria primordial para um bom trabalho na EJA, como possível ver abaixo:

As Secretarias Estaduais de Educação e o próprio MEC deveriam se preocupar em oferecer um programa de formação e orientação que nos capacite para trabalhar com os alunos da EJA e que dê sustentação ao processo de aquisição da leitura e escrita por esses alunos que apresentam grandes dificuldades para aprender a ler de forma fluente e com capacidade crítica $(\mathrm{P} 4)$. 
Durante todo o tempo que atuo na educação regular e na EJA, nunca tive conhecimento de cursos de formação continuada que possibilitasse conhecimento para a alfabetização de adultos. Até mesmo para atuar na escola regular nunca tive conhecimento de cursos que incentivasse e ensinasse usar a leitura como estratégia de ensino da disciplina que ministro que é a Física (P6).

Este discurso encontra sustentação em Silva e Reis (2011) que apontam a necessidade de repensar a formação dos professores para que possam atender a diversidade dos alunos e para romper com a Pedagogia Tradicional. Propõem para isso que essa mudança comece a se efetivar a partir da formação inicial do professor, visando assim "eliminar os vestígios de uma formação tradicional, que tem em sua essência princípios baseados na homogeneidade, na qual o professor vê seu aluno como alguém sem uma identidade, fazendo assim, com que suas práticas atendam às demandas de cada um" (SILVA; REIS, 2011, p. 6).

Esta opinião é também pactuada por Solé (1998) para quem a aprendizagem da leitura se dá a partir do contato com diversos tipos de textos sociais necessários e utilizados no cotidiano e não com caráter meramente didático como, segundo declararam os professores participantes deste estudo, aconteceu nos cursos de licenciatura que frequentaram.

\section{Prática pedagógica para a leitura no PROEJA}

De acordo com Kleiman (2011), a leitura é um processo no qual ocorre o encontro do locutor com o interlocutor através do texto; processo que se encontra sempre mediado pelos contextos linguístico, textual, pragmático-discursivo e que decorre de uma concepção mais ampla de linguagem como interação entre sujeitos em sociedade, também denominada sociointeracionista. Tendo como base estes pressupostos, procuramos compreender como ocorreu a prática da leitura no curso Técnico em Comércio do PROEJA/IFNMG, numa cidade do interior de Minas Gerais.

Os docentes participantes da pesquisa foram questionados sobre a quem, segundo suas opiniões, caberia a responsabilidade de trabalhar a leitura com os alunos. Uma análise das respostas dos docentes para este questionamento demonstra que somente um dos professores considerou que o ensino da leitura é de obrigação dos professores de português, justificando que "muitas disciplinas não disponibilizam de carga horária muito 
grande para desenvolver este trabalho. A minha, por exemplo, são apenas 2 horas/aula, outras têm apenas 1 hora/aula semanal" (P6).

Opinião que vai contra o proposto nos Parâmetros Curriculares Nacionais - PCNs (Brasil, 1997, p. 6) quando orienta ser necessário que os professores às vezes se desprendam da leitura do conteúdo específico de suas disciplinas e que "considerando a multiplicidade de conhecimentos em jogo nas diferentes situações, pode tomar decisões a respeito de suas intervenções e da maneira como tratará os temas, de forma a propiciar aos alunos uma abordagem mais significativa e contextualizada".

Os outros cinco docentes cientes das dificuldades de leitura e interpretação de textos por parte dos alunos do curso Técnico em Comércio do PROEJA/IFNMG - Campus Januária consideraram ser de responsabilidade de todos os docentes o desenvolvimento da competência leitora dos alunos. Entretanto, como pode ser observado nas respostas transcritas a seguir, os docentes investigados se ressentiram da falta de tempo para vencer o conteúdo a ser ministrado e investir em um trabalho de leitura que possibilitasse aos alunos uma prática de leitura mais significativa e que não se limitasse a simples transmissão de conhecimento do conteúdo que trabalham em sala de aula.

O professor deve ter ciência de que o ensino vai além da sua disciplina específica, pois inclui a formação do cidadão. Mesmo pensamento dos docentes do Curso Técnico em Comércio que reconhecem ser de todos eles o dever de investir no desenvolvimento da habilidade de leitura com seus alunos.

Todos nós somos responsáveis por ajudar o aluno a ler de forma fluente, mas nem sempre temos tempo para essa importante ação (P1).

A responsabilidade é de todos os docentes, mas falta tempo para isso (P2).

Todos os professores têm a obrigação de investir na aprendizagem da leitura, pois só quem tem uma leitura fluente consegue interpretar os textos e isso auxilia na aprendizagem de qualquer conteúdo trabalhado em qualquer disciplina (P3).

É de todos os professores e dos envolvidos no processo de ensino e aprendizagem (P4).

Na fala do docente P5 encontra-se implícita a questão da dificuldade e falta de preparo didático-pedagógico dos que não são professores da disciplina Língua Portuguesa para trabalhar a leitura, assim como seu compromisso em assumir a tarefa de ensino da 
leitura, que considera ser de todos, mas que deveria ser melhor implementada nos anos iniciais do ensino fundamental, durante o processo de alfabetização.

\begin{abstract}
A leitura é algo que deve ser começado muito cedo (desde a infância), sendo assim, cabe aos pais ou cuidadores começarem este processo, sendo seguido dos professores, mas de um modo particular o investimento maior deve ser dos de português, porque os demais têm dificuldades por causa da carga horária que é pequena (P5).
\end{abstract}

As respostas dos professores estão em consonância com as orientações do Parâmetros Curriculares Nacionais que atribuem a todos os docentes a tarefa de despertar e estimular no aluno o desejo e o gosto pela leitura, o que pode ser realizado a partir do desenvolvimento de trabalhos de diversas formas e a partir do uso de diversas estratégias e tendo o professor como parceiro, pois só assim ele conseguirá que os mesmos percebam a importância da leitura na sua vida. Neste contexto:

Para tornar os alunos bons leitores - para desenvolver, muito mais do que a capacidade de ler, o gosto e o compromisso com a leitura -, a escola terá de mobilizá-los internamente, pois aprender a ler (e também ler para aprender) requer esforço. Precisará fazê-los achar que a leitura é algo interessante e desafiador, algo que, conquistado plenamente, dará autonomia e independência. Precisará torná-los confiantes, condição para poderem se desafiar a - aprender fazendo. Uma prática de leitura que não desperte e cultive o desejo de ler não é uma prática pedagógica eficiente (BRASIL, 1997, p. 58).

O ato da leitura, conforme declaração dos professores, é muito importante, pois faz parte de um processo ensino-aprendizagem que objetiva a interação dos alunos com informações significativas que poderão auxiliá-los no entendimento e servir como apoio para sua vivência escolar e social e, portanto, deve estar associada:

A concepção de uma política, cujo objetivo da formação está fundamentado na integração de trabalhos, ciências, técnicas, tecnologia, humanismo e cultura geral, pode contribuir para o enriquecimento científico cultural, político e profissional das populações, pela indissociabilidade dessas dimensões necessárias ao efetivo exercício da cidadania (BRASIL, 2006, p. 28).

Cinco dos seis professores declararam ter consciência da importância da leitura no mundo competitivo atual para a formação e exercício da cidadania e visando promover a formação integral dos alunos do PROEJA consideram que o desempenho da competência leitora deve ser priorizado em suas aulas. No dizer destes professores, o exercício da leitora 
pode ser considerado como um ato social, imprescindível para que o aluno possa interagir com as pessoas e o mundo a sua volta.

O mundo atual exige a formação de um cidadão crítico, reflexivo e atuante politicamente em defesa de seus direitos. Por isso a leitura dos diversos gêneros textuais é fundamental para a formação desse cidadão antenado com o seu tempo (P1).

Acho que sim, a leitura deve ser preocupação e prioridade dos professores de todas as disciplinas, pois certamente irá facilitar o entendimento dos temas trabalhados (P2)

O discurso dos docentes P4, P3 e P5, parecem ter como base o pensamento de Kleiman (2011) e Solé (1998) para quem a competência leitora é um importante recurso que possibilita ao aluno a participar ativamente dos acontecimentos que ocorrem a sua volta e eles declaram se preocupar em proporcionar o exercício da leitura com este objetivo.

[...] com a leitura o cidadão torna-se mais crítico e mais preparado para enfrentar os problemas da sociedade (P4).

Considero a leitura como uma base para que o aluno consiga decifrar o mundo em que vive. Sendo assim, a minha preocupação não se resume somente na decifração dos códigos escritos, mas que o aluno consiga, a partir da leitura de mundo que ele já traz quando chega na escola fazer também e principalmente uma interpretação mais crítica dos códigos escritos (P3).

Sim, busco sempre utilizar os textos em minhas aulas, mesmo sendo os textos didáticos, pois a leitura possibilita, além da aprendizagem do conteúdo, a oportunidade do aluno se posicionar diante do que ler (P5).

Privados do direito à educação escolar por muito tempo, por fazerem parte do contingente da população brasileira da qual só se exigia a força física para a execução de tarefas que tinham como intenção aumentar o domínio econômico e o predomínio cultural da classe mais abastada e socialmente dominante, o trabalhador, normalmente aluno da EJA, ainda sofre as implicações da formação de uma sociedade que continua, de acordo Moura (1999, p. 69) dificultando o acesso em participação cultural e educacional de parte da população.

Neste estudo o baixo nível sócio-econômico, o cansaço, o desinteresse, a infrequência dos alunos, aliado à falta de suporte institucional foram fatores que apareceram como grandes dificultadores do trabalho do professor no PROEJA. 
Levando em consideração estas observações de Moura (1999) foi possível observar que o aluno no contexto do PROEJA/IFNMG Campus Januária, apresenta uma realidade diferente da apresentada pela modalidade regular de ensino, e mais, possui características diferentes, o que acaba interferindo no desempenho escolar, demandando dos profissionais desta modalidade de ensino que se encontram inseridos nesta situação atípica, uma urgente transformação no sentido de aprimorar as metodologias, e adaptar o currículo para resultar em uma melhor qualidade da educação oferecida aos jovens e adultos.

Situação que, conforme Carrano (2008), provoca um clima de espanto e perplexidade, nos professores, haja vista o desconhecimento dos espaços e culturas destes alunos. Em alguns casos, os docentes "sentem certo incômodo revelado perante sujeitos que emitem sinais pouco compreensíveis e parecem habitar mundos culturais entendidos, como social e culturalmente pouco produtivos para a escolaridade" (CARRANO, 2008 p. 103). De acordo com os professores participantes deste estudo esse desconhecimento dificulta que eles invistam em processos de ensino de leitura no curso Técnico em Comércio do PROEJA/IFNMG, pois, conforme declaração de um deles: "mal consigo trabalhar o conteúdo da minha disciplina já que os alunos apresentam grandes dificuldades para entender a matéria trabalhada" (P6).

Atitude que vai contra as colocações de Vasconcellos (2000), para quem "a tarefa fundamental do professor não é cumprir o programa, mas ajudar o educando a desenvolver-se e compreender a realidade, sendo o programa um meio para isto e não um fim em si mesmo".

Compreendendo como um dos objetivos do PROEJA a formação leitora de forma crítica e autônoma, os professores definem este tipo de leitor como "aquele que tem a capacidade de compreender a ideia que está sendo transmitida no texto, seja para discordar, concordar ou simplesmente refletir acerca dela" (P3) ou como "o leitor que tem a capacidade de ler, interpretar, criticar e tomar decisões a partir da leitura de um texto" (P5).

Tanto no discurso quanto na prática pedagógica foi possível detectar em dois docentes investigados a existência de uma relação significativa entre a leitura e a aprendizagem, mas com prioridade para atividades de formação para a cidadania, como demonstrado na resposta de alguns deles:

[...] além de permitir a aprendizagem do conteúdo, considero que o trabalho com a leitura proporciona aos alunos a formação para a cidadania, pois os textos dos livros que trabalhamos sempre têm alguma 
mensagem que serve para eles usarem no seu dia, seja no trabalho ou na sua vida social (P4).

[...] um cidadão, inserido em uma sociedade, deve exercer os seus direitos e deveres, deve participar dos processos decisórios do país, e, para isso, é importante a leitura, leitura de símbolos, códigos, placas informativas, textos, enfim, de algum tipo de leitura. E nós professores devemos nos preocupar em proporcionar aos alunos a aprendizagem da leitura dos diversos símbolos existentes (P6).

Para os seis professores que participaram deste estudo, o ensino da leitura não é algo que deveria ser priorizado no planejamento das aulas, mas todos afirmaram a necessidade de realizar um trabalho com o objetivo de ensinar a ler. As colocações de um dos professores do curso Técnico em Comércio do PROEJA/IFNMG Campus Januária ilustra a opinião geral dos participantes do estudo: "cada disciplina trata de um assunto que depende de um tipo de leitura, porém, eu não posso dizer que o ensino da leitura deva ser priorizado no planejamento das aulas porque nem toda disciplina tem um tempo disponível para este fim" (P6).

Com relação à presença do trabalho com a leitura no planejamento da escola, segundo todos os docentes entrevistados, este trabalho está determinado como uma das estratégias de ensino do curso Técnico em Comércio do PROEJA/IFNMG, principalmente por proporcionar a formação completa dos alunos e o equilíbrio emocional dos mesmos e que tem como objetivo tanto o desenvolvimento da capacidade de decodificar códigos como de escrever e que para isso, utilizam os textos didáticos. Os recortes de jornais e revistas também foram citados como sendo utilizados "às vezes" pelos professores.

Segundo P2, “o trabalho com leitura é determinada na grade curricular do curso Técnico em Comércio e tem como um de seus objetivos atingir o equilíbrio entre o desenvolvimento cognitivo e crítico do aluno". O trabalho com a leitura, mais especificamente a literatura é lembrado por Abramovich (1989, p. 18) como de inegável importância "quando se pensa na formação completa do ser humano, num processo que busque o equilíbrio entre o desenvolvimento da inteligência e da afetividade, entre a razão e a emoção, entre o utilitário e o estético."

Os professores se referiram à atitude dos alunos quando leem ou escutam a leitura, considerando que quando propunham este tipo de atividade percebiam que eles ficavam mais concentrados, e desenvolviam atitudes como saber ouvir e interferir na hora apropriada, aspectos importantes quando se refere à socialização dos indivíduos, 
proporcionando "uma melhor e mais concreta aprendizagem e uma maior reflexão sobre a realidade em que viviam (P1). Opinião que deixa evidenciar que o ensino através da leitura possibilita não só o desenvolvimento da linguagem, mas conhecimentos que auxiliam na resolução de problemas e conflitos sociais, familiares, psicológicos, profissionais e que beneficiam o indivíduo e a sociedade e que faz com que como escreveram Nunes et al (2012) na sociedade atual, a leitura se torne imprescindível para o ingresso no mercado de trabalho e para o exercício da cidadania. É uma prática cultural diretamente ligada à escolaridade, capacidade de incentivo à formação e ao aperfeiçoamento de leitores.

No entendimento de Solé (1998, p. 72) formar leitores consiste em capacitar quem lê para "interrogar-se sobre sua compreensão, estabelecer relações entre o que lê e o que faz parte de seu acervo pessoal, questionar seu conhecimento e modificá-lo, estabelecer generalizações que permitam transferir o que foi aprendido para outros contextos diferentes", ou seja, capacitar os alunos para fazer uso do que lê para enfrentar os desafios de sua vida social e profissional. Desafio que deve ser enfrentado pelos professores a partir da implementação de atividades que capacitem os alunos para que, como destaca Kleiman (2011), consigam buscar e selecionar informações que possibilitem aos alunos o entendimento do texto lido, a partir de seu conhecimento de mundo, ou da ativação do conhecimento prévio sobre o assunto. Postura que poderá resultar em um ensino de leitura produtivo que contribuirá para o entendimento do que é lido, ou seja, para a capacitação de leitores proficientes e que motivará os alunos a querer ler cada vez mais.

\section{Considerações finais}

O exame da teoria sobre a concepção e trajetória do PROEJA, a atuação docente e a prática leitora na EJA/PROEJA demonstrou que o PROEJA é uma política pública de inclusão social que surgiu como uma proposta de integração profissional ao ensino médio e buscando a superação da dualidade entre trabalho manual e intelectual, pois além da formação geral se dá a preparação para o trabalho.

Com relação aos professores para atuarem no PROEJA, apesar do esforço dos governos para superar a necessidade de formação de docentes para atender, especificamente, ao ensino de jovens e adultos, este ainda é um dos pontos mais importantes e críticos relacionados a expansão e qualidade do processo ensinoaprendizagem na EJA. 
Os resultados aqui apresentados são relevantes não só para o IFNMG, mas para promover melhoria do ensino na EJA, direcionando um olhar diferenciado para anseios, necessidades, interesses, motivações, condições de vida e outras particularidades dos discentes jovens e adultos que buscam formação em um curso técnico do PROEJA e servindo como documento para pesquisas posteriores.

\section{Referências}

ABRAMOVICH, Fanny. Literatura Infantil. São Paulo, Scipione, 1989

BARDIN, Laurence. Análise de conteúdo. Lisboa: Edições 70, 2009. Disponível em: $\mathrm{http} / / / \mathrm{pt}$. slideshare.net/alasiasantos/analise-de-conteudo-laurence-bardin. Acesso em 11.Jan.2016.

BRASIL. Decreto ${ }^{\circ} 2.208$, de 17 de abril de 1997. Regulamenta o parágrafo $2^{\circ}$ do art. 36 e os artigos 39 e 42 da Lei n. 9394, de 20 de dezembro de 1996, que estabelece as diretrizes e bases da educação nacional. Diário Oficial da República Federativa do Brasil. Brasília, DF, 18 abril 1997.

. Resolução CNE/CEB n¹/2000. Diretrizes Curriculares para a Educação de Jovens e Adultos. Brasília: MEC, 2000.

SECRETARIA DE EDUCAÇÃO CONTINUADA, ALFABETIZAÇÃO E DIVERSIDADE (SECAD). Trabalhando com a Educação de Jovens e Adultos: alunos $e$ alunas do EJA. Brasília, DF: SECAD, (2006a) e (2006b).

BUENO, Belmira Oliveira. Viver a Profissão Pensar a Formação: Contribuições dos Estudos com Histórias de Vida de Professores. In: PIOTTO, Débora Cristina. (Org). Anais da $3^{\mathrm{a}}$ semana da educação: A Profissão Docente em Debate. Ribeirão Preto/ SP: Legis Summa. 2006. p. 96.

CARRANO, Paulo. Identidades culturais juvenis e escolas: arenas de conflitos e possibilidades. In: CANDAU, Vera M.; MOREIRA, Antonio F. (orgs). Multiculturalismo: diferenças culturais e práticas pedagógicas. Petrópolis, RJ: Vozes, 2008. p.182-211.

CRUZ, R. M. R. Limites e possibilidades das tecnologias digitais na educação de jovens e adultos. In: REUNIÃO ANUAL DA ANPED, out. 1994, Caxambu. Trabalhos apresentados... Caxambu: ANPED, 1994. Disponível em: http://www.anped.org.br/reunioes/31ra/1trabalho/GT18-5049--Int.pdf. Acesso em: 12 maio 2016.

CUNHA, Luiz Antônio. O Ensino Profissional na Irradiação do Industrialismo. São Paulo: UNESP; Brasília, DF: Flacso, 2000.

DECLARAÇÃO DE JOMTIEN apud PROPOSTA CURRICULAR, 2002.

DUCROT, O. O dizer e o dito. Campinas, SP: Pontes Editores, 1987. 
FERRÃO, Luís Barata. Formação Pedagógica de Formadores. 4 Ed. Lisboa: Porto Editora, 2004.

FERRAREZI, J. C. Introdução à Semântica de Contextos e Cenários: de la langue à la vie. Campinas: Mercado de Letras, 2010.

FOUCAMBERT, Jean. A leitura em questão. Porto Alegre: Artes Médicas, 1994. 157p.

FREIRE, Paulo. Pedagogia da autonomia: saberes necessários à prática educativa. 31. ed. São Paulo: Paz e Terra, 2005.

GÜNTHER, Hartmut. Como elaborar um questionário. Série: Planejamento de Pesquisa nas Ciências Sociais. N. 1. Brasília: Universidade de Brasília, Instituto de Psicologia, 2003.

KLEIMAN, Ângela. Texto e leitor - aspectos cognitivos da leitura. Campinas, São Paulo: Pontes, $9^{\mathrm{a}}$ ed. , 2011.

MARDEGAN, Flávia. Aprendizagem informal: como os indivíduos aprendem em seus locais de trabalho? Postado em 2013. Disponível em: http://www.abd.org.br/abd/f01/docs/artigos/2013/260313/aprendizagem-informal.pdf> Acesso em: 2 maio 2017.

MINAYO, Maria Cecília de Souza (org.). Pesquisa Social: teoria, método e criatividade. Petrópolis, RJ.: Vozes, 2000.

MOURA. T. de M. A prática pedagógica dos alfabetizadores de jovens e adultos: Contribuições de Freire, Ferreiro e Vygotsky. Maceió: EDUFAL, 1999.

MOURA. T. de M. A Formação de Professores para a Educação de Jovens e Adultos/ Dilemas Atuais. Belo Horizonte: Autêntica. 2007.

NÓVOA, Antonio. Professor se Forma na Escola. Postado em 2001. <http://novaescola.abril.uol.com.br/ed/142-mai01/fala mestre.htm>. Disponível em 13 maio 2016.

RODRIGUES, Neidson. A Escola necessária para os tempos modernos. S.d. Disponível em: http://docs.google.com/viewer. Acesso em: 20 dez. 2016.

SANTOS, Arlete Ramos; VIANA, Dimir. Educação de Jovens e Adultos: Uma Análise das Políticas Públicas (1998 a 2008). In: SOARES, Leôncio. (org). Educação de Jovens e Adultos/ O que revelam as pesquisas. Belo Horizonte: Autêntica. 2011, p.275 ( coleção estudos em EJA).

SILVA, Maurício da. Repensando a Leitura na Escola - Um Outro Mosaico. Niterói, RJ: EDUFF/Diadorim, 1995. 
SILVA, L. R. S.; REIS, M. B. F. Educação Inclusiva: O Desafio da Formação de Professores. Revista de Educação, Linguagem e Literatura da UEG-Inhumas, v. 3, n. 1, mar. 2011.

SOLÉ, Isabel. Estratégias de leitura. 6. ed. Porto Alegre: ArtMed, 1998.

THERRIEN, Jacques. O Saber do Trabalho docente e a Formação do Professor. In: NETO, Alexandre Shigunov (Org). Reflexões sobre a formação de professores. Campinas, SP: Papirus, 2002. p.192.

VEIGA,I. P. A. e SILVA, E. F. da.(org.) A Escola Mudou.Que Mude a Formação de Professores. Campinas, SP: Papirus, 2010.

Recebido em: 31.10 .2018 Aceito em: 12.02.2019 